Authors have nothing to disclose with regard to commercial support.

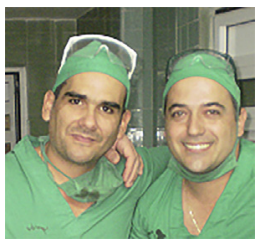

\section{DO NOT FORGET OTHER FATHERS OF CORONARY ARTERY BYPASS GRAFTING!}

\section{To the Editor:}

We have read with great interest the article by Bakaeen and colleagues ${ }^{1}$ dedicated to coronary artery bypass grafting history. We congratulate the authors for the masterful way they managed to summarize fabulous events that have marked milestones in the history of one of the most exciting surgeries.

However, we want to briefly comment on some aspects we believe have not always been addressed with sufficient precision, in relation to the contribution of William Polk Longmire $\mathrm{Jr}$, to the history of cardiac surgery.

In 1990, Longmire confessed to Shumacker that in early 1958, while practicing his technique of directvision coronary endarterectomy, he found, in 2 patients, that it was not possible to repair an extremely calcified coronary artery. In desperation, he anastomosed the internal thoracic artery to the right coronary artery beyond the endarterectomized segment. The surgery was successful. ${ }^{2,3}$

Perhaps because of ethical issues, he decided not to report a too experimental procedure for its time. ${ }^{4}$ For that reason, in its landmark 1958 article, it is impossible to determine exactly the 2 patients who benefited from the technique. It was probably the last 2 operated on, in which curiously no procedure was reported on the right coronary artery. His evolution was favorable; at the time of writing the article, the patients were asymptomatic and without electrocardiographic alterations. ${ }^{5}$

It is usually said that victory has a thousand fathers, but defeat is an orphan.

We consider Favaloro's decision not to credit himself the moniker of "father" of coronary artery bypass surgery very wise. Men such as Arthur Vineberg, William Longmire,

\footnotetext{
The Editor welcomes submissions for possible publication in the Letters to the Editor section that consist of commentary on an article published in the Journal or other relevant issues. Authors should: $\bullet$ Include no more than 500 words of text, three authors, and five references. • Type with double-spacing. • See http://jtcs.ctsnetjournals.org/ misc/ifora.shtml for detailed submission instructions. • Submit the letter electronically via jtcvs.editorialmanager.com. Letters commenting on an article published in the JTCVS will be considered if they are received within 6 weeks of the time the article was published. Authors of the article being commented on will be given an opportunity of offer a timely response ( 2 weeks) to the letter. Authors of letters will be notified that the letter has been received. Unpublished letters cannot be returned.
}

Robert Goetz, and Dudley Johnson also deserve to share that honor.

Yoandy López-de la Cruz, MD, MSc Yolepsis F. Quintero Fleites, MD, MSc Department of Cardiovascular Surgery Santa Clara Cardiac Center Santa Clara, Cuba

\section{References}

1. Bakaeen FG, Blackstone EH, Pettersson GB, Gillinov AM, Svensson LG. The father of coronary artery bypass grafting: René Favaloro and the 50th anniversary of coronary artery bypass grafting. J Thorac Cardiovasc Surg. 2018;155:2324-8.

2. Stoney WS. Bill Longmire and the blue baby operation. J Am Coll Surg. 2004;198: 653-9.

3. Shumacker HB. The Evolution of Cardiac Surgery. Indianapolis: Indiana University Press; 1992.

4. López-de la Cruz Y. William Polk Longmire Jr. and the first 60 years of coronary artery bypass graft surgery. CorSalud. 2018;10:158-63.

5. Longmire WP, Cannon JA, Kattus AA. Direct-vision coronary endarterectony for angina pectoris. N Engl J Med. 1958;259:993-9.

\section{https://doi.org/10.1016/j.jtcvs.2019.06.093}

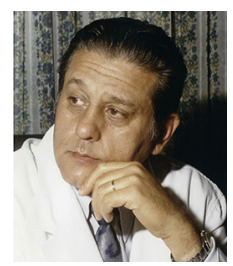

\section{REPLY FROM THE AUTHORS: CORONARY ARTERY BYPASS GRAFTING MAY HAVE MANY FATHERS, BUT ONE STANDS OUT}

\section{Reply to the Editor:}

We appreciate the letter by López-de la Cruz and Quintero Fleites ${ }^{1}$ in this issue of the Journal in which they highlight the important contributions of Dr William Polk Longmire Jr, to the evolution of coronary artery bypass grafting $(\mathrm{CABG})$. They argue that Dr Longmire and other surgeons who contributed to the evolution of CABG should also share the father of CABG honor with Dr Favaloro. ${ }^{1}$ As we mentioned in our history of CABG review, ${ }^{2}$ this honor was bestowed on Dr Favaloro by none other than Dr Denton Cooley, ${ }^{3}$ a surgical statesman who was a vital player and a firsthand witness to the cardiovascular surgical revolution of the second half of the last century that brought us CABG.

Yes, there were others, including Dr Longmire, whom we mention and credit in our review for performing anecdotal venous or arterial CABG in a laboratory or clinical setting, ${ }^{2}$ but it was the seminal publication of the first few hundred patients who underwent CABG with good results and systematic angiographic and clinical follow-up by Sheldon and colleagues ${ }^{4}$ that caught the attention of the world. This was the defining moment for CABG as a safe and reproducible procedure that became the standard of care for coronary artery disease treatment around the globe. It is this intimate association between the work of Dr Favaloro and the rise of CABG that explains and supports 
Authors have nothing to disclose with regard to commercial support.

Dr Cooley's designation of father status to this one man among others who helped move CABG forward.

Faisal G. Bakaeen, MD

Lars G. Svensson, $M D, P h D$

Center for Coronary Revascularization

Department of Thoracic and Cardiovascular Surgery

Heart and Vascular Institute

Cleveland Clinic

Cleveland, Ohio

\section{References}

1. López-de la Cruz Y, Quintero Fleites Y. Do not forget other fathers of coronary artery bypass grafting! J Thorac Cardiovasc Surg. 2020;159:e65.

2. Bakaeen FG, Blackstone EH, Pettersson GB, Gillinov AM, Svensson LG. The father of coronary artery bypass grafting: René Favaloro and the 50th anniversary of coronary artery bypass grafting. J Thorac Cardiovasc Surg. 2018;155:2324-8.

3. Cooley DA. In memoriam. Tribute to Rene Favaloro, pioneer of coronary bypass. Tex Heart Inst J. 2000;27:231-2.

4. Sheldon WC, Favaloro RG, Sones FM Jr, Effler DB. Reconstructive coronary artery surgery. Venous autograft technique. JAMA. 1970;213:78-82.

https://doi.org/10.1016/j.jtcvs.2019.06.095

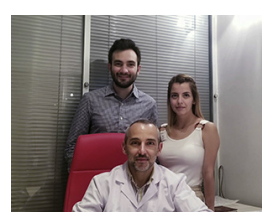

INTERNAL THORACIC ARTERY: A MAJOR COLLATERAL SUPPLY IN CASE OF LERICHE SYNDROME

To the Editor:

We read with great interest the article by Bosse and colleagues, ${ }^{1}$ in which they presented a case series of cardiac surgery combined with bypass from the ascending aorta to the bilateral femoral arteries in patients with severe aorta-iliac occlusion.

Combined coronary artery disease and peripheral vascular disease remain highly common among the population, ${ }^{2}$ and the management of such multivascular disease is usually a clinical challenge in case of Leriche syndrome. In patients with aorta-iliac occlusive disease, interruption of critical collaterals may cause limb-threatening ischemia. Therefore, the left internal thoracic artery (LITA) should be considered with precaution in patients with significant peripheral vascular disease, and lower-extremity perfusion should be fully characterized before coronary artery bypass grafting $(\mathrm{CABG}){ }^{3}$ In patients in whom the lower body flow is established through the LITA, CABG using saphenous vein or gastroepiploic artery grafts may be preferred to not harm important collaterals. ${ }^{3}$ On the other hand, a well-developed LITA may yield a better-quality conduit for CABG and could be used if simultaneous or staged operations of CABG with lower-limb revascularization are considered. The risk/benefit assessment of using the LITA in a combined procedure should be made delicately in these rare cases.

A total of 6 of the 8 patients in this case series underwent combined $\mathrm{CABG}$ procedures. However, the authors do not present information on which conduits were used for CABG, whether patients' lower-extremity perfusion was established through the LITA, and the information about the quality of LITA conduits if used for the CABG operation. Concomitant coronary and peripheral revascularization is used at our institution, ${ }^{4,5}$ as in many others, with promising long mid- to long-term results.

Although conduit selection in CABG combined revascularization in those with Leriche syndrome is controversial because of unclear risk/benefit assessment of using the LITA graft, the 2017 European Society of Cardiology guidelines recommend that the autologous great saphenous vein should be spared for potential future use for surgical peripheral revascularization in patients with advanced lower-extremity arterial disease. ${ }^{6}$ The importance of the LITA collateral for lower-extremity perfusion should be assessed against the importance for giving a chance for future surgical revascularization and delays in the wound healing due to saphenous vein harvesting in severe lowerextremity arterial disease. Contrary to the European Society of Cardiology guidelines, although the LITA is the preferred conduit for the left anterior descending artery bypass during $\mathrm{CABG}$, in this particular patient group, the LITA may be enlarged depending on providing sufficient flow to the lower-extremity perfusion; thus, it may not be a suitable conduit because of the diameter discrepancy between the LITA and the left anterior descending artery. ${ }^{4,5}$

Once again, the authors are to be congratulated for their case series in cardiac surgery combined with ascending aorta bifemoral bypass experience. ${ }^{1}$ However, it would be more informative for the readers if the authors could have provided detailed information about the conduit selection for CABG. This may also be helpful in the future to establish a revascularization protocol together with available literature review in this particular patient population.

Mert Meric, $M D^{a}$

Didem Melis Oztas, $M D^{b}$

Murat Ugurlucan, $M D^{c}$

${ }^{a}$ Istanbul Medical Faculty

Department of Cardiovascular Surgery

Istanbul University

Istanbul, Turkey

${ }^{b}$ Cardiovascular Surgery Clinic

Bagcilar Education and Research Hospital

Istanbul, Turkey

${ }^{c}$ Medical Faculty

Department of Cardiovascular Surgery 